\title{
As metrópoles de Wim Wenders: uma cartografia emocional de Berlim, Lisboa e Tóquio
}

\author{
Janaína Sant'Ana de Andrade ${ }^{1}$
}

\section{Resumo}

Este trabalho buscou compreender a capacidade do cinema em operar como uma plataforma para a exploração geográfica, psíquica e social, por intermédio de uma discussão teórica aliada da análise dos filmes Asas do desejo (Der Himmel über Berlin, Wim Wenders, 1987), O céu de Lisboa (Lisbon Story, Wim Wenders, 1994) e Tokyo-Ga (Tokyo- Ga, Wim Wenders, 1985). Numa reflexão que parte da tomada do cinema como um dispositivo que permite a mobilização espaço corporal, e de tal forma, que se atravesse terrenos de mobilidades socioculturais, obtém-se como resultado a construção do que aqui chamaremos de cartografias emocionais, baseadas numa categoria de Giuliana Bruno (2002). A partir dessas cartografias, buscamos exaltar no cinema, a possibilidade de uma ferramenta para se explorar o mundo junto à antropologia.

Dessa forma, primeiramente procurou-se desconstruir a ideia de que a antropologia deve se ocupar e se apropriar apenas de filmes etnográficos em seu sentido mais estrito. Partindo dessa percepção, os filmes passam a ser compreendidos como produtos culturais, livres de definições acerca de sua forma ou concepção. A ênfase se encontra na combinação de uma abordagem fílmica, juntamente de análises antropológicas, e como resultado a possibilidade de ir além no esforço de compreensão do mundo.

\footnotetext{
1 Iniciação científica, Universidade Federal de São Paulo - Bolsista do Conselho Nacional de Desenvolvimento Científico e Tecnológico. Email: andradejanaina@hotmail.com - Orientadora: Prof. ${ }^{\text {a }}$ Dr. ${ }^{\text {a }}$ Andréa Barbosa
} 
Foi parte da reflexão desta pesquisa a busca de uma leitura cinematográfica que atue como ferramenta para a antropologia, de modo a tornar a compreensão de diferentes camadas de significação da sociedade mais próximas e palpáveis.

Assumimos uma posição posta pela teórica italiana Giuliana Bruno, onde se propõe uma passagem de modelo teórico da forma pela qual se entende o cinema. Saímos da compreensão do cinema como uma ferramenta ótica, para outra onde o cinema se apresenta como uma ferramenta háptica.

Para Bruno (2003), as imagens mentais são construídas hápticamente. Háptico, de acordo com a etimologia grega, significa "possível de se entrar em contato". Sendo uma função da pele, então, háptico - sentido do tato - é constituído do contato reciproco entre nós e o ambiente. Esta função também está relacionada à cinestesia, ou a habilidade dos nossos corpos de sentir o seu próprio movimento no espaço. Desenvolvendo essa lógica observacional, se considera o elemento háptico como um agente na formação do espaço - tanto geográfico como cultural e, por extensão, na articulação das próprias artes espaciais, o que inclui os filmes. Enfatizando o papel cultural do elemento háptico, Bruno desenvolve uma teoria que conecta sentidos a lugar. Aqui, a esfera háptica é exibida desempenhando um papel tangível, tático, em nosso senso de comunicação de espaço e mobilidade, assim dando forma a textura ao espaço habitável e, finalmente, mapeando nossas maneiras de estar em contato com o ambiente. Proveniente diretamente da textura do nosso mundo, essas imagens são de um material elástico, maleável. O tecido do inconsciente é uma imagem em movimento, isto é, pois ele é possuidor do aspecto mais imaginativo do nosso processo cognitivo. Assim, sempre que 
o conhecimento é afetado pela (e)moção ${ }^{2}$, se move. As (e)moções, são produzidas dentro do tecido que tocamos e que nos toca. A sensação háptica é amplamente concebida para alcançar as dobras da experiência.

Para Gilberto Velho (2004) uma questão instigante para a antropologia é a procura pelas experiências suficientemente significativas para a compreensão das construções simbólicas nas sociedades, e têm-se como local por excelência dessas interações de forma mais aguda e nítida as metrópoles contemporâneas. Em um trecho do romance de Ítalo Calvino, As cidades invisíveis, Marco Polo diz ao imperador Kublai Khan que as cidades não contam os seus passados, mas elas os contém "como as linhas da mão, escrito nas esquinas das ruas, nas grades das janelas, nos corrimãos das escadas, nas antenas dos pára-raios, nos mastros das bandeiras, cada segmento riscado por arranhões, serrilhas, entalhes, esfoladuras." (Calvino, p.7, 2002, tradução nossa). ${ }^{3}$ É no cinema, um dos lugares, onde essa relação da cidade com o passado, que sedimenta pouco a pouco um corpo social de significados, se potencializa imageticamente.

É no clássico texto de Simmel sobre a vida do espírito nas grandes cidades de 1903, momento de maior emergência do cinema, que o autor propõe, a partir da intensificação da vida emocional na cidade, a expansão da compreensão do indivíduo pelos limites físicos do seu corpo ou no espaço em que suas atividades físicas estão circunscritas, mas compreende,

\footnotetext{
${ }^{2}$ E)moção busca trazer a relação entre emoção e movimento. Não se busca aqui o afastamento da concepção de emoção proveniente da psicologia, no entanto procura-se trazer também a noção que coloca emoção atrelada a movimento. Traduzido do inglês emotion, que de acordo com o Oxford dictionary, provém do francês émotion, de émouvoir "excitar", baseia-se no latim emovere, $e$ - (variante de ex-)"fora" + movere "movimento". Data do meio do século

${ }^{3}$ No original: come le linee d'una mano, scritto negli spigoli delle vie, nelle griglie delle finestre, negli scorrimano delle scale, nelle antenne dei parafulmini, nelle aste delle bandiere, ogni segmento rigato a sua volta di graffi, seghettature, intagli, svirgole.
} 
ao invés, a totalidade dos efeitos significativos que dele emanam temporal e espacialmente. Da mesma forma, a cidade só existe na totalidade dos efeitos que transcendem a sua esfera imediata. A cidade é disposta como um corpo social, e nos é importante ter em mente, como aponta Velho, "que estamos lidando com conjuntos de símbolos que vão ser utilizados pelas pessoas nas suas interações cotidianas, num processo criativo ininterrupto havendo alguns mais eficazes e duradouros que outros. (p. 17, 2004). Essa proposição vai ao encontro da proposta de Bruno (2002), na qual a cultura urbana - um atlas da carne - floresce no espaço transitório da intersubjetividade. Na mobilização cênica de uma cidade o efeito do siteseeing é produzido, e cria-se no filme um espaço onde é possível não só ver, mas também examinar, perambular, descobrir, reconhecer, perceber e habitar. Como um viajante, o espectador itinerante lê as paisagens em movimento como práticas de imaginação, fazendo das cidades imagens residuais fílmicas em nosso próprio inconsciente espacial. A cidade se torna uma série de levantamentos imaginários descritos pela observação, uma representação geográfica da imaginação tanto para aqueles que conhecem, quanto para aqueles que nunca tinham visto a cidade; ambos os espectadores encontraram o local descrito de forma mobilizada através de memórias.

Dessa forma, optei por trazer o trabalho do cineasta Wim Wenders, de forma a corroborar com a ideia de se pensar o cinema de uma forma antropológica e também com a capacidade de mobilização espaço corporal aqui proposta. Para Wenders, a essência e o propósito do cinema consistem em "apresentar uma imagem do homem em nosso século, uma ferramenta útil e uma imagem válida, na qual ele não só reconhece a si mesmo, mas a partir da qual, acima de tudo, ele pode aprender sobre si mesmo. (Wim 
Wenders, Tokyo-Ga, 1985) ${ }^{4}$ ”. Quanto aos espaços fílmicos, para Wenders "são mais que um "último plano". Eles influenciam os caráteres humanos que vivem neste último plano, criam uma atmosfera, uma noção do tempo, uma certa emoção." (Wenders, 1994, p. 185) e, portanto permitem que o visionemos como um lugar - e também uma cartografia - propícios para mobilizar espaços praticados, bem como para delinearmos nossas próprias cartografias emocionais.

Para Wenders, sua topofilia ${ }^{5}$ se preocupa com a habitabilidade do espaço, e isto envolve o processo de luto, uma resistência que fornece a energia para viajar dentro do espaço para conhecê-lo e descrevê-lo filmicamente. A tríade citadina eleita para análise neste trabalho traz três diferentes aberturas para tratar a habitabilidade destes espaços: a cidade compelida pela história e pela memória, a cidade desconhecida explorada pelo som e a busca da cidade relicário.

Finalizei o trabalho apresentando uma leitura mais atenta da Berlim, da Lisboa e da Tóquio cartografadas por Wim Wenders, e com base nestas procurei realizar um balanço sobre de que forma esta prática investigativa pode nos fazer pensar sobre as questões postas pela antropologia.

Na Berlim de Asas do desejo, encontramos a cidade compelida pela história e pela memória. Para o cineasta (1991), que é natural de Düsseldorf, é Berlim a cidade que oferece de forma mais palpável a genuína experiência do que é a Alemanha, pois nela as histórias e estórias, que em outros lugares estão suprimidas ou negadas, se encontram

\footnotetext{
${ }^{4}$ No original: to present an image of Man in our century, a usable tool and valid image in which he not only recognizes himself, but from which above all he may learn about himself.

${ }^{5}$ Conceito criado pelo geógrafo Yi-Fu Tuan, topofilia é o elo afetivo entre a pessoa e o lugar ou ambiente físico. Difuso como conceito, vívido e concreto como experiência pessoal.
} 
fisicamente e emocionalmente presentes. É nessa toada que Wim Wenders busca um filme não somente em Berlim, mas um filme sobre Berlim e sobre as pessoasque nela habitam ou já a habitaram, e na qual o céu é a única testemunha permanente. É deste céu sobre Berlim ${ }^{6}$ que provêem os anjos Damiel (Bruno Ganz) e Cassiel (Otto Sander), os quais acompanhamos vagar pela cidade descrita por Wenders como um local histórico da verdade e um lugar de sobrevivência.

Já a Lisboa de $O$ céu de Lisboa é a cidade desconhecida, ainda que o cineasta tenha estado duas outras vezes na cidade para a filmagem de outros dois de seus filmes. Neste filme, a intenção de Wenders (1994) era refletir sobre o que é, hoje em dia, a apropriação de uma cidade através de imagens e sons. $\mathrm{O}$ filme resulta de um convite a Wenders para homenagear a capital européia da cultura do ano de 1994, inicialmente esperado em forma de documentário, mas que acaba por tornar-se uma ficção. Uma ficção, descrita pelo próprio diretor, "de como, com imagens e sons, podemos nos guiar numa cidade desconhecida." (Wim Wenders, $O$ céu de Lisboa, 1994)6. Exploramos a cidade junto de Philip Winter (Rüdiger Vogler), um engenheiro de som alemão que a convite de seu amigo e diretor Friedrich Monroe (Patrick Bauchau) vai a Lisboa ajudálo na produção de um filme. Ao chegar à cidade, Winter encontra o filme inacabado e seu diretor desaparecido, no entanto o fascínio que a cidade e seus moradores exercem sobre ele, o fazem ficar.

E é na Tóquio de Tokyo-Ga que encontramos a cidade relíquia, mas não uma relíquia qualquer - uma relíquia da memória. A Tóquio que se busca vem diretamente da memória de Wenders, ornamentada pelos filmes do cineasta japonês Yasujiro Ozu. O filme na forma de documentário, ou

\footnotetext{
6 Tradução literal do título do filme.
} 
como chama o diretor um "diário em filme", visita inusitados lugares de Tóquio e conversa com importantes presenças da obra cinematográfica de Ozu, como o ator Ryu Chishu e o diretor de fotografia Yuharu Atsuta. O filme toma forma a partir da busca de traços, imagens e pessoas que habitaram os filmes de Ozu, numa cidade inscrita no imaginário de Wenders. Cidade esta que para o cineasta estava posta na obra de Ozu como grandes momentos e extensões da realidade, elementos raros no cinema de hoje para Wenders. É, portanto, dessas três cidades que partimos para buscar uma leitura, uma mobilização emocional e cartográfica, aqui através dos filmes, de cidades que inscreveram na história suas minúcias e singularidades, através do cinema.

Palavras Chave: antropologia urbana, antropologia visual, cinema

\section{Referências}

BARBOSA, Andréa . São Paulo cidade azul: ensaios sobre as imagens da cidade no cinema paulista dos anos 80. São Paulo: Alameda Casa Editorial, 2012.

BENJAMIN, Walter. "Berlin Chronicle” In: One-way street and other writings. Londres: Verso, 1992.

BENJAMIN, Walter. "A obra de arte na era da sua reprodutibilidade técnica" $e$ " $O$ Narrador” In: Obras escolhidas: Magia, técnica, arte e política: ensaios sobre literatura e história da cultura. São Paulo: Brasiliense, 1985.

BRUNO, Giuliana. Atlas of Emotions: Journeys in Art, Architecture and Film. Nova York: Verso, 2002.

Pleats of Matter, Folds of the Soul. Log - No. 1 (Fall 2003), pp. 113-122.

Publicado por: Anyone Corporation. Disponível em: <http://www.jstor.org/stable/41764958> . "Motion and Emotion: Film and the Urban Fabric." In: Andrew Webber and 
Emma Wilson (org.) Cities in Transition: The Moving Image and the Modern Metropolis. Londres: Wallflower Press, 2008.

CALVINO, Italo. Le città invisibili. Milão: Oscar Mondadori, 1993.

EISENSTEIN, Sergei M. Eisenstein. Montage and Architecture. Translation from Russian: Michael Glenny. Assemblage - No. 10 (Dec., 1989), pp. 110-131. Publicado por: The MIT Press. Disponível em: 〈http://www.jstor.org/stable/3171145>

LEACH, Edmund. Sistemas políticos da alta Birmânia: um estudo da estrutura social kachin. São Paulo: Edusp, 1995.

MERLEAU-PONTY, Maurice. “The Spatiality of One's own Body and Motility” In: Phenomenology of Perception. Londres e Nova York: Routledge, 2002.

METZ,Christian. "Identification, Mirror" In: The Imaginary Signifier. Bloomington: Indiana University Press, 1982.

PESSOA, Fernando. Livro do Desassossego. São Paulo: Companhia das letras, 2000.

PESSOA, Fernando. “35 Sonnets” in Poemas Ingleses. Lisboa: Ática, 1974.

SIMMEL, Georg. “A Metrópole e a Vida Mental” In Velho, Otávio Guilherme (org.), O Fenômeno Urbano. Rio de Janeiro: Guanabara, 1967.

VELHO, Gilberto. Individualismo e cultura: notas para uma antropologia da sociedade contemporânea. Rio de Janeiro: Zahar, 2004

VELHO, Gilberto; VIVEIROS DE CASTRO, Eduardo. O conceito de cultura e o estudo de Sociedades complexas. ESPAÇO: Cadernos de cultura USU. 2 (2): 11-26, 1980.

WENDERS, Wim. "A Paisagem Urbana" In: Revista do Patrimônio Histórico. Rio de Janeiro: IPHAN, n. 23, 1994.

WENDERS, Wim. The Logic of Images: Essays and Conversations. Londres: Faber and Faber, 1991.

\section{Filmografia}

ASAS do desejo. Direção: Wim Wenders. Fotografia: Henri Alekan. Golden Images, 1987. 1 DVD (128 min), Preto e Branco. Título original: Der Himmel Uber Berlin. 
VIAGEM a Lisboa. Direção: Wim Wenders. Fotografia:Lisa Rinzler. Atlanta Filmes, 1994. 1 DVD (100 min), Color. Título original: Lisbon Story.

TOKYO-GA. Direção: Wim Wenders. Fotografia: Ed Lachman.Europa Filmes, 1985. 1 DVD (92 min), Color. Título original: Tokyo-Ga. 